\title{
Mathematics Emerging: from Colorado to Oxford
}

Abstract: History of mathematics courses based on original source materials are becoming increasingly common. But are they more suitable for particular types of students? Here we compare two such upper-level courses, with a similar structure and using the same textbook, taken by liberal arts students at Colorado College and mathematics specialists at Oxford University.

\section{Source-based courses}

Many mathematics curricula include a traditional history of mathematics course. Such courses use comprehensive survey texts that cover a wide range of world mathematical history, and there are a number of excellent texts written for this purpose, such as those by Uta C. Merzbach and Carl B. Boyer [7], David M. Burton [2], Victor J. Katz [4], and William Berlinghoff and Fernando Gouvea [1].

In recent years an attractive alternative has been a course devoted to reading original sources. In such courses, students tend to delve more deeply into fewer topics and gain a more direct experience of mathematics as done in distant times and places. This usually raises the mathematical level of the course, and is especially valuable for students who are not trained in historical thinking. Such courses can more easily meet the separate goals of providing a good understanding of mathematical history, while also using the historical perspective to develop a deeper understanding of the mathematics involved.

Instructors wishing to use this approach can face the daunting task of creating their own lists of readings from printed or online sources. An alternative is to find a sourcebook of suitable material to draw from, such as the classic works of David Eugene Smith [8] and Dirk Jan Struik [10], but their selections seem a little eccentric to modern eyes and the translations are often less than desirable, especially when they stray too far into modern notation and terminology.

A well-known sourcebook by Fauvel and Gray [3] is usable in some circumstances, but many of its translations are still quite old and it includes more ancient mathematics than instructors might wish. Based on the influential Open University course MA290, which placed great emphasis on original source material, it is less suitable for a course with much modern content.

Exciting alternatives have been provided by Reinhard Laubenbacher and David Pengelley and their colleagues [5], [6]. These texts examined particular topics from the history of 
mathematics through the use of brief original source extracts, supplemented by extensive discussion and exercises. Although their choice of topics is excellent and they develop them well, an instructor using these books is inevitably tied to these topics and students do not benefit from the unmediated experience of trying to read original sources without modern commentary and exposition.

The very different history of mathematics courses at Colorado College and Oxford University, which we discuss below, both use Jacqueline Stedall's Mathematics Emerging: A Sourcebook 1540-1900 [9] as a text. This sourcebook includes over 130 short original extracts, drawn mostly from the modern era of European mathematics as described in the title. These are presented in facsimile as they first appeared, with new English translations supplied (see Figure 1). There is a short and pertinent introduction for each one, but no extended explication or discussion. The extracts cover most of traditional pure mathematics, although there are some gaps in coverage, such as 19th-century geometry and number theory.

Figure 1 [double-page spread]: Two pages from Mathematics Emerging.

\section{Colorado College}

Colorado College is a liberal arts college in Colorado Springs, founded in 1874 and with an enrollment of about 2000 undergraduate students. It is well known for its unusual teaching structure, based on the 'block plan', where the college year is split into eight courses ('blocks') of three-and-a-half weeks' duration. During each block, students study a single subject in a small class (maximum 25 students) with an assigned instructor in an allocated room. The daily timetable is flexible and is left to the instructor and the class. Before each day's class, the students are expected to have assimilated the previous day's material, and usually to have completed a homework assignment on it. Before they can become mathematics majors, students must complete second-level courses in linear algebra and number theory, and normally take 12 15 blocks of mathematics in total before graduating.

Figure 2: History of mathematics students from Colorado College.

Over the years, Colorado College has presented a number of courses in the history of mathematics, ranging from introductory ones taken when the students first arrive to specialist courses in their final year. In recent years seniors have been required to take one of two "capstone" options: a year-long independent project culminating in a thesis and a lecture to the mathematics department, or a fourth-year sources-based course on the history of mathematics 
which also requires the writing of a major research paper. It is this history of mathematics course that we will focus on here. It has the following specification:

MA 408: A study of selected developments in the history of mathematics and the role of mathematics in different cultures across time. The course often draws on original sources and traces the relationships among different fields within mathematics through the in-depth study of major unifying results.

The prerequisites for taking this course are senior standing and the standard undergraduate introductions to abstract algebra and real analysis. Students are thus expected to have some relatively sophisticated understanding of mathematics (if not history). In recent years it has usually been taught by Marlow Anderson, and on one occasion by Robin Wilson.

From the beginning the emphasis has been on using original sources: the idea is that placing ideas from their algebra and analysis courses in their original contexts should help students to understand these subjects better. Although the course has used the Laubenbacher-Pengelley and Fauvel-Gray volumes, the choice in recent years has been Mathematics Emerging. A typical block covers about half of this book, with an emphasis on standard topics from the students' previous algebra and analysis courses. The text contains many such extracts that are both mathematically sophisticated and historically interesting.

Because of the complementary thesis requirement, the enrollment for MA 408 is usually small, ranging from four to ten students. These students have usually taken a range of basic mathematics courses, including the two mentioned in the prerequisites, but not necessarily any more advanced ones. As liberal arts students, they are fully accustomed to writing essays and to presenting material on the board in the classroom, but few have previously undertaken a major historical project. The students in the course range over the full spectrum of mathematical ability, among Colorado College senior mathematics majors.

Normally the class sessions take place for two to three hours each day. In preparation for a typical class, all students are expected to have worked through the day's extracts in advance. Each day pairs of students ("facilitators") lead the class discussion on specific extracts. These facilitators are either selected by the instructor, or volunteer themselves. They are expected to provide context and insight, with further contextual remarks provided by the instructor who also helps with difficult passages. These facilitators change from day to day, so that during the course each student will be paired with all of his/her classmates. For the most part, students select their own partner facilitator and also the extract they wish to present on a given day. 
Assessment takes four forms. Part of the course grade is allocated to class participation. In addition, on most days there is a substantial written mathematical assignment, due the next day, on mathematical issues thrown up by the day's extracts. The assignments often involve solving a problem using the historical methods discussed in class, or else typical problems from across the mathematics curriculum, which illuminate the modern version of a topic discussed. There are also a couple of examinations during the block, which may involve commenting on short mathematical extracts, writing short historical essays, or working through mathematical exercises. Two examples of extracts that have been set are the following:

\section{Proposition I, Theorem I}

The areas which revolving bodies describe by radii drawn to an immovable centre of force do lie in the same immovable planes, and are proportional to the times in which they are described.

Isaac Newton

A function $f x$ varies according to the law of continuity for all values of $x$ inside or outside certain limits means that if $x$ is some such value, the difference $f(x+\omega)-f x$ can be made smaller than any given quantity provided $\omega$ can be taken as small as we please.

Bernard Bolzano

Another type of question asks students to compare different approaches to a particular problem. An example is:

Newton, Euler, and Cauchy all encounter situations where they need to compute a limit of a ratio of two terms, each going to zero (most famously when computing a derivative, but also in other contexts). Write an essay comparing their approaches. Be sure to include some comments on the language they use, and what use they made of concepts like "infinitely small" or "infinitesimal". How close did they come to the "modern" definition of a limit?

A central requirement of the course is to prepare a major research paper on a topic of the student's choice, after discussion with the instructor. These papers should demonstrate strong mathematics and history, with substantial mathematical content (which usually restricts the topic to the 17 th century or later) while addressing some serious historical issues. As preparation for this task, the students are generally required to produce an outline and bibliography for their proposed paper, and to proceed with a topic only after discussing it with the instructor. The papers are to be carefully written, with mathematical typography and a full bibliography, and are also presented as a lecture to the rest of the class. In recent years, they have included such topics as Gauss and the development of the method of least squares, Pascal and Fermat's problem of 
points and the rise of probability theory, Euler's development of number theory, and Noether and the rise of axiomatic ring theory.

The course has generally been popular with students, attracting such comments as this: "The History of Math was one of my favorite courses I took at CC and was a wonderful way to wrap up my academic career there."

\section{Oxford University}

At Oxford University mathematics students study mathematics alone for three or four years, leading to an undergraduate degree. With three eight-week terms each year (and further work required during the vacations), the students spend the first four terms learning the core material of linear and abstract algebra, real and complex analysis, applied mathematics, probability, and statistics. After this, particularly from their third year onwards, they are free to specialize and can study a wide range of mathematically related options.

Among these options is a course (O1) on the history of European mathematics from 1600 to 1900. Although most of the students taking this course will have studied mathematics at a greater depth than their Colorado counterparts, they will not have benefited from a liberal-arts training in essay writing and communication skills. In many cases, the Oxford students have not written an essay since their high-school days.

Figure 3: The Oxford Mathematical Institute, with the Radcliffe Observatory (c.1770) in the background.

In 2003 four Oxford historians of mathematics, Peter Neumann, Jacqueline Stedall, Raymond Flood, and Robin Wilson, designed the $\mathrm{O} 1$ course as a means of providing the historical background for the core mathematics that the students had studied in their first four terms. For several years it was taught by these four mathematicians, but it later became the sole responsibility of Jacqueline Stedall. It is now taught by Christopher Hollings, and typically has about ten students per year.

It was during Jacqueline Stedall's years of teaching the course that she recognized the need for a single textbook that included the basic source material from 1600 to 1900 in translation. Her book Mathematics Emerging is now used as course and assessment material for O1. As in Colorado, the course usually covers material from about half of the book.

The course has two main components. The first component consists of 16 one-hour lectures which the students attend in the first term of their third year. These lectures cover the main 
course material and are supported by classes held every two weeks. During this lecture component the students are required to write four 1000-word essays, commenting on the context, content, and significance of specified historical extracts. The essays written for these classes do not count towards the final mark for the course, but are intended to prepare students for assessment at the end of the academic year. Here is a typical essay example:

It has sometimes been claimed that Fermat should be considered as one of the founders of the calculus. More recently, the Fundamental Theorem of Calculus has been attributed by some to Gregory and Barrow. What arguments can be given for or against such claims? What does it mean to say that Newton or Leibniz 'discovered' the calculus? Does being 'first' matter?

In addition, students are given topics to prepare for the discussion classes. These classes usually begin with an overview of major points from the essays, and include general advice as necessary on writing about the history of mathematics. Each of these discussion classes has a specific extract selected. Students prepare to discuss the extract in class under the following headings:

Context: When, where and for whom was the piece written? What mathematical background does it assume?

Content: Work through the content as carefully as you can, noting the parts that are particularly difficult or tricky. Is the argument convincing? How does it differ, if at all, from the way in which this mathematics is presented nowadays?

Significance: How important was this piece of work in the historical development? Have opinions on this piece changed over the years?

At the end of the academic year, the lecture component is assessed by a two-hour examination paper in June, administered by the university; it is blind-marked and doublemarked. It consists of two parts. In the first part the students comment on two (out of six) sources. Two recent examples are:

Whence it is clear how rare are the perfect numbers, and how rightly they are compared to perfect men; and that it is one of the most difficult of all mathematical problems to exhibit a list of a collection of perfect numbers; just as also to understand whether given numbers consisting of 15 or 20 digits, are prime or not, since not even a whole lifetime is sufficient to examine this, by any method so far known.

Marin Mersenne 
Substitutions are the passage from one permutation to another . . As the concern is always with questions where the original disposition of the letters has no influence, in the groups that we will consider one must have the same substitutions whichever permutation it is from which one starts. Therefore, if in such a group one has substitutions $S$ and $T$, one is sure to have the substitution $S T$.

Évariste Galois

In the second part of the examination, students write one essay from a choice of three topics. Recent examples are:

Discuss and assess the contributions of René Descartes to the mathematics of the 17 th century.

Discuss the evolution of the concept of a function from the early 18 th to the late 19 th century.

Discuss, with reference to specific examples, the changing standards of rigour in mathematics from the 17 th to the 19 th centuries.

Having developed some historical and writing skills, and having become used to reading historical sources, students take a reading course in their second term, as the second component of the year-long course. This is based on a specific topic with weekly seminars in which the students discuss what they have been reading. The topic of the reading course changes from year to year, and has focused on such topics as Newton's Principia Mathematica, the development of rigor in 19th-century analysis (with translated readings from Lagrange, Bolzano, and Cauchy), the development of the notion of a group (Galois, Cauchy, and Cayley), and the development of the Quadratic Reciprocity Theorem (Euler, Legendre, and Gauss).

The reading component is assessed by a 3000-word essay, prepared at the end of the second term of the academic year. It is also blind-marked and double-marked; the essay and the examination are weighted equally towards the final grade. The specific topic for the essay is given out in the 7th week of term and the students have three weeks to research and write the essay. Whereas the shorter essays that the students wrote during the term are on general topics, this extended essay demands greater depth.

Since the History of Mathematics course is rather different from the courses that Oxford mathematics students are used to, both in its content and its assessment, those who elect to take it often do so with some degree of trepidation: the need to write essays is often a major concern. An important goal of the course work is thus to build the confidence in the students that they can in fact do the work. On the whole, the students usually find their voice after only two or three 
assignments, and the 'new' mode of communication poses few problems. Two or three of the students who take the course typically go on to write a 10,000-word dissertation on a historical topic in their fourth year. Anecdotally, students have often commented on the benefits that they have gained from taking the History of Mathematics course, both for their communications skills and for the context that they have gained for their broader mathematical studies.

\section{Comparisons and contrasts}

It is interesting to compare and contrast the Colorado and Oxford courses.

\section{Comparisons}

There are several features in common with the Colorado College and the Oxford University course. They are both taken by a small number of students late in their undergraduate career, with most of these students coming new to the history of mathematics. Both courses concentrate mainly on source material from 1600 to 1900, using the same textbook Mathematics Emerging [9], with about half of the book covered. Both courses require that students engage in both the mathematical content and the historical context of the sources, by expecting that they be actively involved in discussions of the course material. Both courses are assessed by a written examination and the writing of a substantial essay or project. Both courses emphasize the history of mathematics, and not the history of mathematicians. Both emphasize writing and discussions which highlight the context, content, and significance of original sources.

\section{Contrasts}

The main difference is that the two courses cater for different types of student - in Colorado the liberal arts students have a basic mathematical background and a wealth of experience of essay writing, involvement in discussions, and experience in presenting their knowledge at the board to a class. In Oxford the highly trained mathematics students often have little or no background in essay writing or with involvement in discussions, but the mathematics covered is sometimes at a deeper level than at Colorado, with more opportunity to discuss more technical topics at Oxford.

There are further contrasts. The Colorado course takes less than four weeks, while the Oxford course lasts for a whole year (including the final examination). In Colorado the students play a major role in the presentation of the course; the Oxford course is more 'instructor-led'. In Colorado all aspects of the assessment (course participation, daily homework, examinations, and extended essay) count towards the grade for the course: in Oxford only the final examination and extended essay count. 


\section{Conclusion}

In conclusion, what we find interesting and gratifying is that, despite the major differences in the institutions and in the students taking the course, an original source-based history of mathematics course can succeed in deepening the students' understanding of important mathematical topics, and in giving them real insight into how the discipline developed. Students at Oxford gain confidence in reading and writing about the history of mathematics, and at Colorado students have an opportunity to encounter the ideas from their undergraduate curriculum in new and illuminating contexts.

At both institutions, the students in the course are talented and mathematically wellprepared, which makes it easier for it to be a success. In addition, instructors need to have some historical background and knowledge to make a sources-based book work, without relying on the framework of a general textbook on mathematical history. With this caution, we believe that our model is worth trying at many undergraduate institutions.

\section{References}

1. William P. Berlinghoff and Fernando Gouvea, Math Through the Ages: A Gentle History for Teachers and Others, expanded 2d edn., American Mathematical Society, 2015.

2. David M. Burton, The History of Mathematics: An Introduction, 7th edn., McGraw-Hill, 2010.

3. John Fauvel and Jeremy Gray (eds.), The History of Mathematics - A Reader, Macmillan, 1987.

4. Victor J. Katz, A History of Mathematics, 3d edn., Pearson, 2008.

5. Arthur Knoebel, Reinhard Laubenbacher, Jerry Lodder, and David Pengelley, Mathematical Masterpieces: Further Chronicles by the Explorers, Undergraduate Texts in Mathematics, Springer, 2007.

6. Reinhard Laubenbacher and David Pengelley, Mathematical Expeditions: Chronicles by the Explorers, corrected edn., Undergraduate Texts in Mathematics, Springer, 2013.

7. Uta C. Merzbach and Carl B. Boyer, A History of Mathematics, 3d edn., John Wiley \& Sons, 2011.

8. David Eugene Smith, A Source Book in Mathematics, Dover Publ., 1984.

9. Jacqueline Stedall, Mathematics Emerging: A Sourcebook 1540-1900, Oxford University Press, 2008.

10. Dirk Jan Struik (ed.), A Source Book in Mathematics, 1200-1800, 1st edn., 1969; revised edn., Princeton University Press, 2014. 
